\title{
PRODUÇÃO E CARACTERIZAÇÃO DE (HEMI)CELULASES DE Aspergillusniger OBTIDAS POR DIFERENTES SISTEMAS DE CULTIVO
}

\author{
V. M. VASCONCELLOS ${ }^{1,2}$, R. L. C. GIORDANO ${ }^{1}$, P. W. TARDIOLI ${ }^{1}$ e C. S. FARINAS ${ }^{1,2}$ \\ ${ }^{1}$ Universidade Federal de São Carlos, Departamento de Engenharia Química \\ ${ }^{2}$ Embrapa Instrumentação, Laboratório de Agroenergia, São Carlos \\ E-mail para contato: vanessamolina_10@yahoo.com.br
}

RESUMO - As celulases e xilanases, enzimas capazes de hidrolisar a biomassa vegetal, podem ser obtidas através de diferentes técnicas de cultivo, microrganismos e substrato indutor, diferenciando assim as características dos extratos enzimáticos produzidos. O presente trabalho avaliou a produção enzimática pelo fungo filamentoso Aspergillus niger utilizando diferentes métodos de cultivo (em estado sólido, submerso e combinado) e diferentes substratos indutores (bagaço de cana pré-tratado por explosão a vapor lavado e não lavado e com pré-tratamento hidrotérmico). A melhor condição foi o cultivo em estado sólido com o bagaço hidrotérmico, com atividades de 116,7 $\pm 14,3,92,7 \pm 26,5$ e 975,4 $\pm 105,8 \mathrm{UI} / \mathrm{mg}$ de proteína para endoglucanase, $\beta$-glicosidase e xilanase, respectivamente. Além disso, os extratos apresentam termoestabilidades distintas, indicando diferenças não só quantitativas, mas também qualitativas para as diferentes condições de cultivo.

\section{INTRODUÇÃO}

Os resíduos agrícolas e agroindustriais, devido à variedade, disponibilidade e baixo custo, destacam-se como matéria-prima para a produção de etanol celulósico, também chamado de etanol de segunda geração(2G).No Brasil, aproximadamente 350 milhões de toneladas de resíduos são produzidos anualmente,originados principalmente da cana-de-açúcar e da soja (Pereira Jr. et al., 2008). O bagaço de cana-de-açúcarapresenta como principais componentes a celulose (32-44\%), a hemicelulose (27-32\%) e a lignina (19-24\%) (Soccolet al., 2010).

Três classes principais de enzimascompõem o complexo enzimático celulolítico:as endoglucanases (1-4- $\beta$-D-glucanglucanohidrolases), exoglucanases $\quad$ (exo 1,4- $\beta$-Dglucancelobihidrolase)e $\beta$-glucosidases ou celobiases. Essasenzimas atuam em regiões distintas dacadeia celulósica, porém, de forma sinérgica (Zhang et al., 2006). A atuação de enzimasacessórias como as xilanases também é de grande importância para desestruturar oentrelaçamento da hemicelulose presente na parede celular vegetal, facilitando o acesso àcelulose (Dodd e Cann, 2009).

O desenvolvimento de bioprocessos eficientes para a produção das celulasese xilanasesse faz necessário para tornar economicamente viável a conversão do material 
lignocelulósico(Farinas et al., 2010). Nesse sentido, diversas linhas de pesquisa estão sendo estudadas, tais como:avaliação de diferentes linhagens de microrganismos capazes de produzir celulases, condições operacionais para produção dessas enzimas (Delabona et al., 2012), técnicas de cultivo (Cunha, 2012),tipo de biomassalignocelulósica e tecnologia de pré-tratamento escolhido (Farinas, et al, 2010).

O fungo filamentoso Aspergillusniger destaca-se com a produção de um complexo enzimático contendo celulases, xilanases e outras enzimas acessórias (Farinas et al., 2010; Sohailet al., 2009).Aexpressãocelulolíticadeste microrganismoé influenciada pelo substrato indutor e suas enzimas são consideradas termoestáveis (Farinas et al., 2010; Castro, et al., 1997).

As celulases podem ser produzidas por diferentes bioprocessos. Os processos convencionais mais conhecidos são a fermentação em estado sólido (FES), caracterizada pelo cultivo em substrato sólido e umidade controlada, e a fermentação submersa (FSm), realizada na presença de água. O processo não convencional chamado de fermentação combinada (FC) foi desenvolvido por Cunha et al. (2012). Esse novo processo é caracterizado pela elaboração de um pré-cultivo com etapa inicial no estado sólido e posterior transição para cultivo submerso, ou seja, é uma combinação dos dois processos convencionais.

Devido a recalcitrância do material lignocelulósico, para uma eficiente produção e hidrólise enzimática, é necessário primeiramente submeter o material a um pré-tratamento, tornando a celulose mais acessível para o microrganismo ou para o ataque enzimático (Kim, 2009). Os processos de pré-tratamento das biomassas lignocelulósicas podem ser térmicos, químicos, físicos, biológicos ou uma combinação dentre eles.A escolha do pré-tratamento dependerá do grau de separação requerido e do processo fermentativo que será utilizado.

Frente a isso, o presente estudo avaliou a influência na produção e a estabilidade térmica dos extratos enzimáticos produzidos por $A$. nigerem diferentes técnicas de cultivo(fermentação em estado sólido, submersa e combinada) utilizandodiferentes tipos de bagaço de cana-de-açúcar como substrato indutor(bagaço pré-tratado por explosão a vaporlavado (BEx-lav) e não lavado (BEx), e bagaço pré-tratado hidro termicamente (BHt).

\section{MATERIAIS E MÉTODOS}

\subsection{Microrganismo}

Como agente fermentador foi utilizadoo A. niger (3T5B8) pertencente à coleção da Embrapa Agroindústria de Alimentos (Couri e Farias, 1995). Os conídios, mantidos sob congelamento a $-18^{\circ} \mathrm{C}$, foram ativados em meio batata dextrose ágar (BDA) a $32^{\circ} \mathrm{C}$ por 5 dias.

\subsection{Matéria-Prima Lignocelulósica}

Foi utilizado como substrato lignocelulósico indutor o bagaço de cana-de-açúcar prétratado por explosão a vapor não lavado (BEx), o BEx lavado com água morna $\left(50-60^{\circ} \mathrm{C}\right)$ até 


\section{9 a 22 de outubro de 2014 \\ Florianópolis/SC}

atingir o $\mathrm{pH}$ neutro (BEx-lav), e o bagaço in natura pré-tratado hidro termicamente(BHt) no Departamento de Engenharia Química da UFSCar, emreator Parr, $195^{\circ} \mathrm{C}$ por 10 minutos.O material seco foi selecionado por peneiramento na faixa granulométrica $0,50 \leq X \leq 2,00 \mathrm{~mm}$.

\subsection{Condições de Pré-Cultivo Submerso e Combinado}

Os procedimentos descritos envolvendo as condições de pré-cultivo e a produção enzimática foram realizados para cada substratoe foram realizadas repetições em triplicata.

Meio de cultivo: O meio de cultivo utilizado foi o meio descrito por Mandels eSternberg (1976), adaptado por Cunha et al. (2012).

Procedimento de pré-cultivo submerso (FSm): os esporos ativados em BDA foram ressuspendidos e inoculados diretamente no meio líquido. Foram inoculados $10^{7}$ esporos $/ \mathrm{mL}$ de meio de cultivo, descrito na secção 2.3 , enriquecido por $30 \mathrm{~g} / \mathrm{L}$ de glicose e $\mathrm{pH}$ inicial 4,5 . A incubação foi mantida em mesa incubadora rotativa a $200 \mathrm{rpm}, 32^{\circ} \mathrm{C}$ por $48 \mathrm{~h}$.

Procedimento de pré-cultivo combinado (FC): A primeira etapa foi realizada em estado sólido,no qual $10^{7}$ esporos/g de substrato sólido foram inoculados diretamente sobre a matéria prima lignocelulósica.Posteriormente a homogeneização, a umidade do substrato indutor foi ajustada com a adição do meio de cultivo descrito na secção 2.3, sem a suplementação de glicose, na proporção de $12 \mathrm{~mL}$ por $5 \mathrm{~g}$ de substrato sólido, os frascos permaneceram incubados em estufa à $32^{\circ} \mathrm{C}$ por $24 \mathrm{~h}$. Após esse período iniciou-se a segunda etapa, que consistiu na transição dos pré-cultivos para a fermentação submersa através da adição de meio líquido descrito na secção 2.3 enriquecido com $30 \mathrm{~g} / \mathrm{L}$ de glicose com pH inicial 6,0. Os fracos foram mantidos em mesa incubadora rotativa a $200 \mathrm{rpm}$ e $32^{\circ} \mathrm{C}(\mathrm{Cunha}$ et al.,2012).

\subsection{Produção Enzimática}

Fermentação em estado sólido: a produção enzimática por essa metodologia dispensa a etapa de pré-cultivo e assemelha-se com a primeira etapa do pré-cultivo combinado, porém os frascos permanecem incubados por um período de $72 \mathrm{~h}$. Para a obtenção dos extratos enzimáticosfoi realizada a extração com a adição de tampão acetato de sódio $0,2 \mathrm{M}$ e pH 5,0, na proporção 1:10 (sólido/líquido). Os frascos foram mantidos em mesa incubadora rotativa a 120 $\mathrm{rpm}, 32^{\circ} \mathrm{C}$ por $40 \mathrm{~min}$. A suspensão foi filtrada e o extrato enzimático obtido foi centrifugado a $11.000 \mathrm{rpm}$ por $15 \mathrm{~min}$ e mantido a $-80^{\circ} \mathrm{C}$ para posteriores análises enzimáticas.

Fermentação submersa e combinada: a produção de celulases e xilanases foi realizada em frascos de Erlenmeyer de $500 \mathrm{~mL}$ contendo $100 \mathrm{~mL}$ de volume útil, composto pelo meio de cultivo descrito na secção 2.3 enriquecido com $10 \mathrm{~g} / \mathrm{L}$ de glicose, $1 \%(\mathrm{~m} / \mathrm{v})$ da matéria prima lignocelulósica e inoculados com $10 \%$ (v/v) do caldo do pré-cultivo. Os frascos foram incubados em mesa incubadora rotativa a $200 \mathrm{rpm}$ por $72 \mathrm{~h}$ à $32^{\circ} \mathrm{C}$. No final das $72 \mathrm{~h}$ as amostras foram filtradas, centrifugadas e armazenadas para análise nas mesmas condições da FES. 


\section{9 a 22 de outubro de 2014 \\ Florianópolis/SC}

\subsection{Procedimento Analítico}

Atividade de endoglucanase: a atividade de endoglucanase foi determinada a $50^{\circ} \mathrm{C}$, tendo como substrato uma solução de carboximetilcelulose $0,4 \%$ em tampão citrato de sódio 0,2M, pH 4,8, por 10 minutos de acordo com adaptações na metodologia de Ghose (1987).

Atividade de xilanase: a atividade de xilanase foi determinada utilizando-se como substrato uma solução de xilana $1 \%$ em tampão acetato de sódio $0,2 \mathrm{M}, \mathrm{pH} 5,0$, por 5 minutos à $50^{\circ} \mathrm{C}$ segundo Bailey e Poutanen (1989).

Para as atividades descritas acima uma unidade de atividade enzimática (UI) corresponde a $1 \mu$ mol de grupos redutores liberados por minuto de reação. Os açúcares liberados foram determinados pelo método de DNS segundo Miller (1959).

Atividade de $\beta$-glicosidase: a atividade de $\beta$-glicosidase foi determinada utilizando como substrato uma solução de celobiose $0,015 \mathrm{M}$, preparada em tampão citrato de sódio $0,05 \mathrm{M}, \mathrm{pH}$ 4,8, incubando-se um volume de enzima apropriado em um $\operatorname{lmL}$ de substrato, durante 30 min à $50^{\circ} \mathrm{C}$. A reação é interrompida por submersão em água fervente por 5 min. A quantificação da glicose liberada foi determinada por um kit enzimático (Doles, Brasil).

Análise de Bradford: as proteínas presentes no extrato foram quantificadas a partir do micro-ensaioda metodologia deBradford (1976), os resultados foram expressos em $\mathrm{mg}$ de proteína/mL equivalente a albumina do soro bovino (BSA).

Estabilidade Térmica: para os ensaios de estabilidade térmica o complexo enzimático permaneceu incubado em condições estáticas, em banho termostático à $50^{\circ} \mathrm{C}, \mathrm{pH} 4,8$ por 24 horas, as alíquotas foram retiradas após 10, 60, 120, 240, 360, 480, 720 e 1440 minutos, e imediatamente resfriadas em banho de gelo para interromper a reação de inativação e analisadas de acordo com os procedimentos de atividades descrito na seção 2.4. Os resultados foram ajustados utilizando um método exponencial não-linear de Sadana e Henley (1987) A partir da Equação (1) foi possível calcular a constante de inativação térmica, na qual $A r$ é a atividade relativa (adimensional), $\alpha$ é a relação entre a atividade específica no estado final e inicial, $k_{d}$ é a constante de inativação térmica de primeira ordem $\left(\mathrm{min}^{-1}\right)$ e $t$ é o tempo de incubação da solução enzimática (min). O tempo de meia vida foi definido como o tempo necessário para que ocorra uma redução de $50 \%$ da atividade inicial.

$$
A r=(1-\alpha) * \exp \left(-k_{d}^{*} t\right)+\alpha
$$

\section{RESULTADOS E DISCUSSÃO}

Ao todo, foram avaliados 9extratos enzimáticos para se determinar a influência da matéria-prima lignocelulósica e da técnica de cultivo na indução da síntese enzimática por $A$. niger, empregando-se separadamente o bagaço de cana-de-açúcar explodido e lavado (BEx- 
lav), explodido e não lavado (BEx), e hidrotémico (BHt), nas técnicas de fermentação em estado sólido (FES), submersa (FSm) e combinada (FC) (Tabela 1).

A Tabela 1 apresenta os resultados das atividades enzimáticas (UI.mL ${ }^{-1}$ ) para os extratos enzimáticos obtidos. Utilizando o BEX nos cultivos em FES o fungo não foi capaz de produzir enzimas, mas aFSm e a FC apresentaram atividades maiores em relação aos outro substratos indutores. A FES destacou-se por fornecer condições mais favoráveis para a produção de endoglucanase e xilanases pelo A. niger 3T5B8, enquanto que a FSm e a FC resultaram maiores atividade para as $\beta$-glicosidases.

Tabela 1 - Atividades enzimáticas (UI/mL) das (hemi)celulases avaliadas.

\begin{tabular}{ccccc}
\hline \multirow{2}{*}{ Tipos de Cultivo } & Substrato & Endoglucanase & $\beta$-glicosidase & Xilanase \\
\cline { 3 - 5 } & & & UI.mL & \\
\hline \multirow{2}{*}{ FES } & BEx-lav & $3,04 \pm 0,03$ & $2,2 \pm 0,4$ & $23,5 \pm 0,8$ \\
& BHd & $2,43 \pm 0,12$ & $1,9 \pm 0,6$ & $20,5 \pm 1,4$ \\
& BEX & - & - & - \\
\hline \multirow{2}{*}{ FSm } & BEx-lav & $0,57 \pm 0,04$ & $5,0 \pm 0,4$ & $4,9 \pm 0,3$ \\
& BHd & $0,63 \pm 0,03$ & $6,0 \pm 0,6$ & $3,5 \pm 1,1$ \\
& BEX & $0,91 \pm 0,02$ & $7,4 \pm 0,1$ & $4,4 \pm 0,2$ \\
\hline \multirow{2}{*}{ FC } & BEx-lav & $0,53 \pm 0,01$ & $5,0 \pm 0,1$ & $2,9 \pm 0,2$ \\
& BHd & $0,50 \pm 0,01$ & $5,4 \pm 0,2$ & $1,0 \pm 0,1$ \\
& BEX & $0,75 \pm 0,01$ & $6,8 \pm 0,3$ & $5,0 \pm 0,4$ \\
\hline
\end{tabular}

A Figura 1 ilustra as atividades específicas (UI/mg de proteína) encontradas para endoglucanase, $\beta$-glicosidase e xilanase. O extrato enzimático produzido em FES utilizando-se BHt destaca-se como a melhor condição para a produção das (hemi)celulases, apresentando os melhores resultados com atividades de 116,7 $\pm 14,3,92,7 \pm 26,5$ e 975,4 $\pm 105,8 \mathrm{UI} / \mathrm{mg}$ de proteína para endoglucanase, $\beta$-glicosidase e xilanase, respectivamente.

Para a linhagem de A.niger utilizada, a FES destaca-se como melhor metodologia de cultivo para a produção de endoglucanases e xilanases, enquanto a FSm e FC não apresentam diferenças significativas entre si. A síntese de $\beta$-glicosidase apresenta-se pouco susceptível não somente à metodologia utilizada para a produção da enzima como ao substrato indutor utilizado.

Durante os pré-tratamentos térmicos e químicos uma série de compostos são gerados, devido às condições operacionais empregadas, sendo que esses compostos podem atuar como inibidores. Os principais produtos da degradação se agrupam em três categorias: derivados furânicos, ácidos orgânicos fracos e derivados fenólicos (Kim, 2013).

Nesse estudo a lavagem do bagaço de cana-de-açúcar explodido pode ter influenciado diretamente para o processo de síntese enzimática. Para a FES a lavagem é uma operação crucial para o crescimento e desenvolvimento do A. niger, pois ao se utilizar o BEx sem o procedimento de lavagem não foi possível detectar o crescimento do fungo filamentoso, assim como nenhuma atividade enzimática. Para a FSm e FC a lavagem não aumenta significativamente a atividade 
enzimática. Segundo Kim (2013) a lavagem do material pré-tratado a vapor com água quente $\left(90^{\circ} \mathrm{C}\right)$ remove compostos como oligossacarídeos e fenólicos que atuam como inibidores na hidrólise enzimática e na fermentação com leveduras.
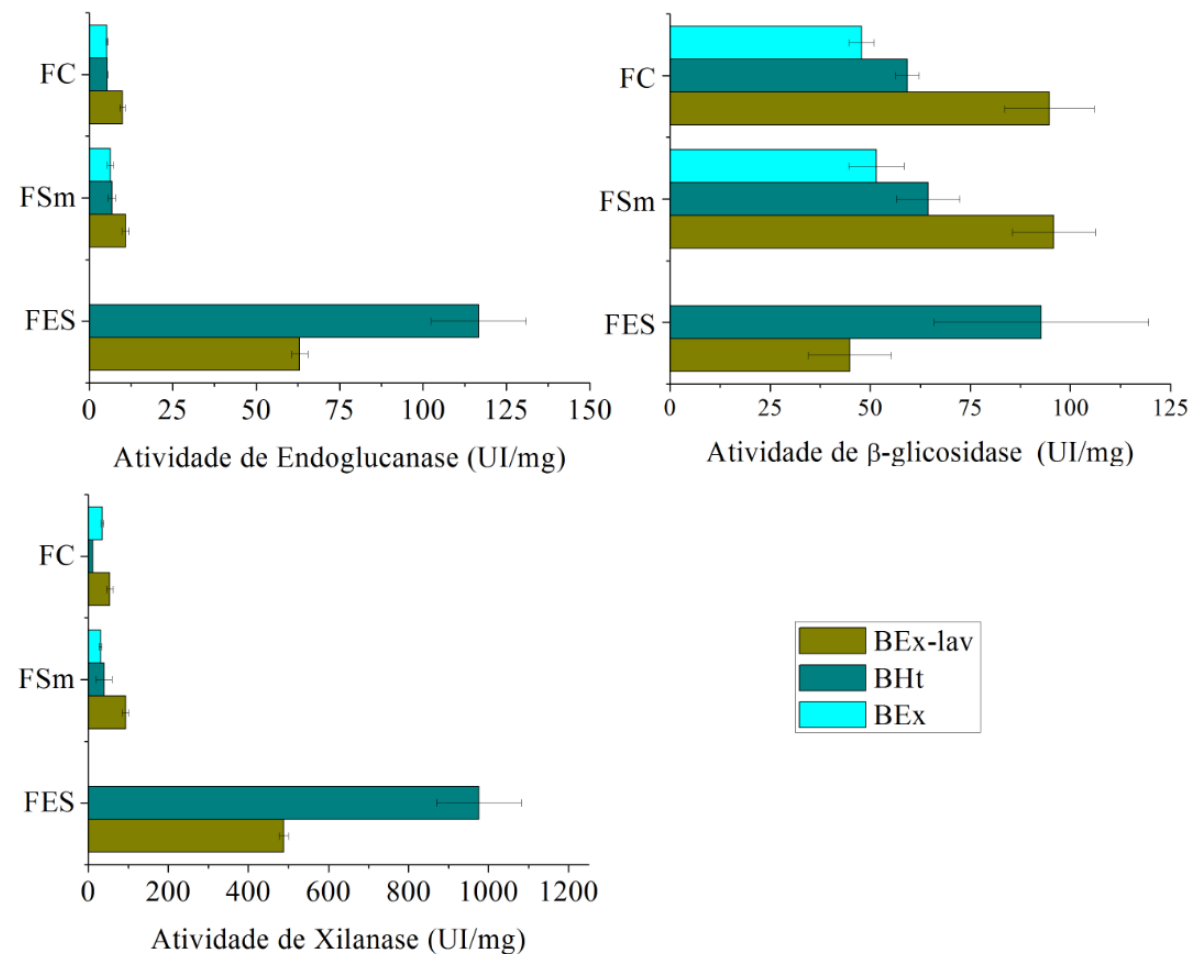

Figura 1 - Atividade enzimática específica (UI/mg) de endoglucanase, $\beta$-glicosidase e xilanase.

A Tabela 2 lista os resultados de estabilidade térmica para as três classes enzimáticas estudadas.Algumas condições avaliadas não se ajustaram ao modelo de Sadana e Henley (1987), pois não atingiram valores iguais ou inferiores a $50 \%$ de atividade residual retida (A.R.) após 1440 minutos de incubação a $50^{\circ} \mathrm{C}$ e pH 4,8 e, portanto, não foi possível determinar os tempos de meia vida para estes coquetéis celulolíticos. A condição operacional utilizada assemelha-se a utilizada em processos de hidrólise do material lignocelulósico.

As enzimas produzidas por FES apresentaram resultados melhores em termos de termoestabilidade.Para o parâmetro estabilidade térmica a lavagem da matéria prima também se apresenta como uma etapa vantajosa para todas as técnicas de cultivo estudadas.

A forma de cultivo e o material lignocelulósico indutor influenciaram severamente na estabilidade térmica dos coquetéis enzimáticos produzidos. As xilanases são as enzimas que apresentaram menor estabilidade a $50^{\circ} \mathrm{C}$. Para essa classe enzimática as melhores condições foram a combinação BEx-lav na FSm e na FC, apresentando 50\% de atividade depois de 1440 minutos de incubação. Castroet al. (1997) avaliaram atermoestabilidade dasxilanasesproduzidasporumalinhagem de Aspergillustermotolerante em FSmna ausência de substrato e os resultadosmostraram que as enzimas mantinham50\% e30\% da sua atividadedepois 
de30minutosincubadas. Assim a combinação BEx-lav na FSm destaca-se, em termos de termoestabilidade, para processos no qual o interesse são as xilanases.

Tabela 2 - Resultados dos ensaios de termoestabilidade para as (hemi)celulases, atividade retida (A.R.) após 1440 minutos de incubação a $50^{\circ} \mathrm{C}, \mathrm{pH} 4,5$ e tempo de meia vida.

\begin{tabular}{cccccccc}
\hline $\begin{array}{l}\text { Tipo de } \\
\text { cultivo }\end{array}$ & $\begin{array}{c}\text { Substrato } \\
\text { Indutor }\end{array}$ & \multicolumn{2}{c}{ Endoglucanase } & \multicolumn{2}{c}{$\beta$-glicosidase } & \multicolumn{2}{c}{ Xilanase } \\
\hline \multirow{6}{*}{ FES } & & $\begin{array}{c}\text { A.R. } \\
(\%)\end{array}$ & $\begin{array}{c}\mathrm{t}_{1 / 2} \\
(\mathrm{~min})\end{array}$ & $\begin{array}{c}\text { A.R. } \\
(\%)\end{array}$ & $\begin{array}{c}\mathrm{t}_{1 / 2} \\
(\mathrm{~min})\end{array}$ & $\begin{array}{c}\text { A.R. } \\
(\%)\end{array}$ & $\begin{array}{c}\mathrm{t}_{1 / 2} \\
(\mathrm{~min})\end{array}$ \\
& BEx-lav & 80 & - & 100 & - & 11 & 59 \\
& BHt & 90 & - & 100 & - & 26 & 76 \\
\multirow{3}{*}{ FSm } & BEX & - & - & - & - & - & - \\
\hline \multirow{3}{*}{ FC } & BEx-lav & 90 & - & 75 & - & 50 & - \\
& BHt & 75 & - & 8 & 533 & 34 & 908 \\
& BEx & 0 & 156 & 2 & 249 & 0 & 57 \\
\hline & BEx-lav & 95 & - & 90 & - & 50 & - \\
& BHt & 24 & 92 & 0,5 & 144 & 0 & 450 \\
& BEx & 19 & 113 & 3 & 321 & 0 & 56 \\
\hline
\end{tabular}

NOTA. Não foi possível estimar o tempo de meia vida para os coquetéis enzimáticos que apresentaram A.R. $\geq 50 \%$.

De modo geral, observou-se que a escolha do substrato lignocelulósico indutor, o tipo de pré-tratamento utilizado e a forma de cultivo podem influenciartanto na atividade comona termoestabilidade enzimáticadas enzimasendoglucanase, $\beta$-glicosidase e xilanase. Para a utilização desses extratos nos processos de sacarificação e fermentação alcóolica, as condições operacionais devem ser atentamente analisadaspara uma melhor adequação quantitativa e qualitativa dos extratos enzimáticos.

\section{CONCLUSÃO}

A medida de atividade enzimática e a estabilidade térmica dos extratos enzimáticos produzidospela linhagem $A$. nigerfoi diretamente influenciada tanto pelo material lignocelulósico quanto pela técnica de cultivo. A melhor condição estudada foi através daFES com BHt, para as três enzimas avaliadas(endoglucanase, $\beta$-glicosidase e xilanase). Os extratos enzimáticos apresentaram termoestabilidades distintas, sendo que os melhores valores de estabilidade foram para os extratos produzidos por FES usando BHte FES comBEx-lav para endoglucanase e $\beta$ glicosidase.Para as xilanases o processo de FSm usando BEx-lav e FC com BEx-lavapresentaram os extratos enzimáticos com melhores valores para termoestabilidade.

\section{REFERÊNCIAS}

BAILEY, M.J.; POUTANEN, K.; Production of xylanolytic enzymes by strains of Aspergillus. ApplMicrobiolBiotechnol, n.30, p.5-10, 1989. 


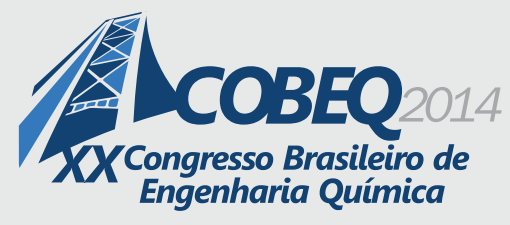

19 a 22 de outubro de 2014
Florianópolis/SC

BRADFORD, M. M. Rapid and sensitive method for quantification of microgram quantities of protein utilizing principle of protein-dye binding. Anal Biochem,v. 72, p. 248-254, 1976

CASTRO, L. P. M.; TREJO-AGUILAR, B. A.; OSORIO, G. A. Thermostablexylanases produced at $37^{\circ} \mathrm{C}$ and $45^{\circ} \mathrm{C}$ by a thermotolerantAspergillus strain. FemsMicrobiol. Lett. 146, 97102, 1997

COURI, S.; FARIAS, A. X. Genetic manipulation of Aspergillus niger for increased synthesis of pectinolytic enzymes. Revista De Microbiologia, v. 26, n. 4, p. 314-317, Oct-Dec 1995.

CUNHA, F.M.; BACCHIN, A.L.G.; HORTA, A.C.L.; ZANGIROLAMI, T.C.; BADINO, A.C.;

FARINAS, C.S. Indirect method for quantification of cellular biomass in a solidscontaining medium used as pre-culture for cellulase production. BiotechnolBioproc Eng. N. 17, p. 100-108, 2012.

DELABONA, P.; PIROTA, R.D.P.; CODIMA, C.A.; TREMACOLDI, C.R.; RODRIGUES, A.; DODD, D.; CANN, I. Enzymatic deconstruction of xylan for biofuel production.Glob. Change

Biol. Bioenergy, 1, 2-17. 2009.

FARINAS, C. S.; LOYO, M. M.; BERALDO Jr. A.; TARDIOLI, P. W.; NETO, V. B.; COURI, $\mathrm{S}$. Finding stable cellulase and xylanase evaluation of the synergistic effect of $\mathrm{pH}$ and temperature. New Biotechnol, v. 27, n. 6, p. 810-815, Dec 2010.

GHOSE, T.K. Measurement of cellulaseactivies. Pure \&ApplChem, Oxford, v.59, n.2, p. 257268, 1987.

KIM, Y.; KREKE, T.; HENDRICKSON, R.; PARENTI, J.; LADISCH, M. R. Fractionation of cellulase and fermentation inhibitors from steam pretreatedmixed hardwood. BioresTechnol, v. 135, p. 30-38, 2013.

KIM, Y.; MOSIER, N. S.; LADISCH, M. R. Enzymatic digention of liquid hot water pretreated hybrid poplar. BiotechnolProg, Vol. 25, N. 2, p. 340-348, 2009

MANDELS, M.; STERNBERG, D. Recent advances in cellulase technology. Fermentation Technol. n.54, p.256-286, 1976.

MILLER, G.L. Use of dinitrosalicilic acid reagent for determination of reducing sugar. Anal. Biochem., v. 31, p. 426-428, 1959.

PEREIRA JR, N., COUTO, M. A. P. G., SANTA ANNA L. M. M. Biomass of Lignocelulosic Composition for fuel ethanol production within the context of biorefinery.Series onbiotechnology. Rio de Janeiro: Escola de Química/UFRJ, v.2, 2008.

SADANA, A.; HENLEY, J. P. Single-step unimolecular non-first-order enzyme deactivation kinetics. BiotechnolBioeng, v. 30, p. 717-723, 1987.

SOCCOL, C.R.; VANDENBERGHE, L.P.S.; MEDEIROS, A.B.P.; KARP,S.G.; BUCKERIDGE, M.S.; RAMOS, L.P.; PITARELO, A.P.; FERREIRALEITÃO,V.;GOTTSCHALK, L.M.F.; FERRARA, M.A.; BON, E.P.S.; MORAES, L.M.P.; ARAÚJO, J.A.; TORRES, F.A.G. Bioethanol from lignocelluloses:status and perspectives in Brazil. BioresourTechnol,n.101, p.4820-4825, 2010.

SOHAIL, M.; SIDDIQI, R.; AHMAD, A.; KHAN, S. A. Cellulase production form Aspergillus niger MS82: effect of temperature and pH.New Biotechnol, v. 25, n. 6, p. 437-441, 2009.

ZHANG, Y-H.P.; HIMMEL, M. E.; MIELENZ,J. R. Outlook for cellulase improvement: screening and selection strategies. Biotechnol. adv. v.24, p.452-481, 2006. 